\title{
An Examination of Perceived Relational Messages that Accompany Interpersonal Communication Motivations
}

\author{
Gwen A. Hullman*, Audrey Goodnight and Jessica Mougeotte
}

Division of Communication Studies, University of Nevada, Reno Mail Stop 0229 Reno NV 89557-0229, USA

\begin{abstract}
Interpersonal scholars are concerned about what motivates people to communicate with one another, and how motivation manifests itself in dyadic interaction. Rubin, Perse, and Barbato (1988) identified the main motives for interpersonal communication: control, inclusion, affection, relaxation, pleasure, and escape. Although Myers and Ferry (2001) examined interpersonal communication motives and immediacy behaviors in general, there is a dearth of research addressing how nonverbal cues or messages correlate to motives in specific communication events. Examining the nonverbal layer that accompanies a verbal message is an important step in interpersonal communication motives research.

Most of the meaning of a message is derived from the nonverbal layer of the message (Mehrabian, 1969). Incongruent verbal and nonverbal messages are more difficult to interpret than are congruent messages (Burgoon \& Bacue, 2003). In addition, the sender of incongruent messages might "come across as smug, insincere, or patronizing" (p. 194). Schrader (1994) found, however, that messages attempting to convince an adversary were rated more appropriate when accompanied by nonverbal indicators of immediacy and intimacy, not dominance. In this case, incongruent behaviors preserved a favorable impression of the sender. Given these findings, it makes sense to examine whether or not nonverbal messages seem to complement or contradict the motivation of the message.

Nonverbal cues normally tell us little about the messages when viewed in isolation from one another. Burgoon and Hale (1984) argued that relational messages encompass "both the verbal and nonverbal expression that indicate how two or more people regard each other, regard their relationship, or regard themselves" (p. 193). Although they identified several relational messages, Dillard, Solomon, and Palmer (1999) argued that substantive relational messages could be subsumed into two larger categories: dominance and affiliation.

This study examines how nonverbal cues are interpreted in terms of dominance and affiliation for messages motivated by the three primary interpersonal communication motives: control, inclusion, and affection. The findings will illuminate how speakers package messages according to the motive for the communication.
\end{abstract}

Keywords: Relational Messages, interpersonal communication, motivations.

\section{RELATIONAL MESSAGES}

Relational level messages represent meaning about a relationship between two people, but are separate from the verbal words of the message (Burgoon, 1994). Relational communication focuses on the meanings mainly associated with nonverbal behavior (Burgoon, 1994; Siegman, 1978; Thayer, 1986). Discreet nonverbal behaviors are normally packaged in such a way that their compositions constitute relational evident in the typology developed by Burgoon and Hale (1987).

Interpersonal interactants can express a diverse set of relational messages (Burgoon \& Hale, 1987). Burgoon and Hale (1987) developed a typology of themes to represent the meaning of messages (Relational Dimensions Instrument). According to Burgoon and Hale (1987), there are seven themes: intimacy, emotional arousal, composure, control,

*Address correspondence to this author at the Division of Communication Studies University of Nevada, Reno Mail Stop 0229 Reno NV 89557-0229 USA; Tel: (775) 784-1788; Fax: 7757841175;

E-mails: gwenh@unr.edu,gwenhullman@hotmail.com similarity, formality, and task-social. These relational level messages are conveyed through nonverbal communication. Although the dimensions are categories themselves, they each represent a continuum on which to place a perception (Burgoon \& Hale, 1987). For example, one can communicate and be perceived as somewhat dominant, really dominant, or not dominant at all. Some research focuses on the nonverbal relational messages that are conveyed by specific nonverbal behaviors. A sample of these is presented first. Second, other scholars have focused on additional variables that are related to the presence of certain nonverbal relational messages.

Burgoon, Buller, Hale, and deTurck (1984) found that the distance between two people and the posture of a person affects perceived relational messages. Specifically, greater intimacy, attraction, trust, and caring are perceived when the sender is closer rather than farther away. However, closer proximity to the target of message might also convey greater dominance, persuasiveness, aggression, and intimacy. Burgoon (1991) found similar results that indicate closer proximity communicated more dominance, similarity, immediacy, and composure. In addition, when the sender leans forward while smiling and briefly touches the receiver, 
the receiver reports messages of intimacy, composure, and informality. Again, similar findings for posture were reported in Burgoon (1991). She found that for opposite-sex attractive pairs of people, an open posture indicates more trust and composure. Open posture was related to more composure for males and females. In addition, when status was equal, moderate posture indicated more similarity.

Eye gaze and touch also influence relational messages. Burgoon, Coker, \& Coker (1986) found that gaze aversion during interviews was related to less immediacy, less credibility, and less attraction. For males and females who held a high reward for the receiver of the message, males who employed the high gaze were rated as more dominant whereas females who employed high eye gaze were rated as more submissive. Burgoon, Walther, and Baesler (1992) found that the use of casual touch conveyed nonverbal relational messages such as greater immediacy, greater affection, trust, relaxation, similarity, and informality. The effect of touch in this study was moderated by valence of the toucher.

Perceived relational messages also affect other perceived characteristics of the sender such as conversational involvement (Burgoon \& LePoire, 1999; Burgoon \& Newton, 1991; Capella, 1983; Coker \& Burgoon, 1987). Capella (1983) states that "proximity, lean, orientation, gestural activities, smiling, gazing, laughing, and touch," in addition to paralinguistic cues signal involvement in a conversation (p. 117). Coker and Burgoon (1987) attempted to have subjects regulate their behavior based on if they wanted to appear involved in a conversation with another person. Participants wishing to appear highly involved demonstrated behaviors such as leaning forward toward the other person, relaxed laughter, fewer latencies in speech, fewer silent moments in speech, and more coordinated speech. Highly involved participants also were more attentive to the other person instead of objects around them. Burgoon and LePoire (1999) found similar relationships between conversational involvement and dimensions intimacy, dominance, composure, and informality. Burgoon and LePoire (1999) and Burgoon and Newton (1991) validated the perceptions of the receiver with perceptions of an observer. Clearly, perceived conversational involvement is influenced by perceived relational messages.

Attraction and liking are also influenced by relational messages. Burgoon et al. (1992) and Mehrabian (1969) found that nonverbal relational messages are related to attraction or liking. For example, Mehrabian (1969) concluded that eye contact increases as a person reports higher levels of attraction until the attraction level become very high. At the highest point, the amount of eye contact decreases slightly. Body orientation, for females, is turned toward a person who is liked, and away from a person who is not liked. On the other hand, males who report a high level of liking for another tend to slightly turn the body away from the other person. Boderman et al. (1972) and Fisher, Rytting, and Heslin (1975) reported higher levels of liking for those in a touch versus no touch conditions in ESP and library experiments. In addition, Burgoon, et al. (1986) found that gaze aversion was associated with less attraction.
The literature suggests that nonverbal cues are typically interpreted in conjunction with one another as opposed to individually. Nonverbal cues are also interpreted in relation to their verbal counterparts. The aggregate effect of the cues results in an impression. To successfully decode messages receivers must take into account the goals and intentions of the sender. Understanding a communication motive assists individuals in deciphering pragmatic meaning in the messages of others (Wyer \& Adaval). In addition, receivers must take into account the literal value of the message (Fussell \& Krauss, 1989; Lau \& Chiu, 2001). "In many instances, a recipient may simply assume that a communicator's statement is intended to be taken literally without much deliberation. In other cases, however, a recipient may be stimulated to consider more carefully the communicator's motives for conveying the message and in doing so, may infer that the message's literal meaning was not the meaning the communicator actually wished to transmit" (Adaval \& Wyer, 2004, p. 303). In the case that the verbal and nonverbal communication messages match one another, the sender might be considered more efficient in communicating to fulfill his or her motives. In the case that the motive for communicating doesn't align with the relational message displayed, problems in understanding might arise or the sender might also be more strategic in packaging a message.

\section{INTERPERSONAL COMMUNICATION MOTIVES}

The interpersonal communication motives perspective grew out of a combination two separate research agendas. The first was developed by Schutz (1966) who posited three reasons that people need to communicate interpersonally with one another. He named inclusion, affection, and control as the three interpersonal needs. The second research area is uses and gratifications (Katz, Blumler, \& Gurevitch, 1974). Uses and gratifications states that humans have media needs that they are aware of and that they attend to media that will gratify the needs they have. This research is based on a functional view of communication where one is fully aware of his or her own needs and the alternatives available to fulfill those needs. In short, people know why they communicate. They choose to communicate with others interpersonally to fulfill a psychological need.

Although Schutz (1966) originally posited control, inclusion, and affection as the three interpersonal needs, Rubin and Martin (1998) argued that psychological needs (as identified by Maslow, for example) may be fulfilled by communication with others. Control, inclusion, and affection, then manifest themselves as primary motives for communicating.

\section{CONTROL}

Control indicates "communicating for instrumental compliance-gaining purposes" and occurs in both intimate and non-intimate relationships (Graham, Barbato, \& Perse, 1993, p. 173). Communicating for control is positively related to neuroticism and psychoticism (Paulsel \& Motett, 2004). Those who reported both an internal locus of control and an external locus of control by powerful others reported communicating for control (Rubin \& Rubin, 1992). 
Non-intimate relationships include co-workers and taskoriented group members. Machiavellian subordinates communicate with their superiors for control, but tend to be less satisfied with them (Walter, Anderson, \& Martin, 2005). In a small group setting, communicating for control is negatively related to perceptiveness, responsiveness, attentiveness, and group satisfaction (Anderson \& Martin, 1995a). In turn, communicating for control in a small group setting is positively related to loneliness (Anderson \& Martin, 1995a).

Communicating for control is linked to a conformity orientation in families (Barbato, Graham, \& Perse, 2003). Family relationships are an example of intimate relationships. In a study of young adults and their fathers, young adults reported communicating with their fathers for control reasons, which was also positively related to satisfaction with the relationship (Martin \& Anderson, 1995).

A few studies report results from elderly samples. Control relates negatively to the elderly people's use of humor (Barbato et al., 1995). Contextual age, arguably a better predictor than chronological age (Barbato \& Perse, 1992) encompasses attributes that characterize one's life position, such as life satisfaction, mobility, and loneliness. Elderly whose contextual age is higher (i.e., less mobile, less healthy, and less socially active) reported communicating for control reasons.

Characteristics of the sender's communication attributes also have been examined in conjunction with the control motive. Control-motivated messages conforming to conventional design logic were judge more effective and appropriate than those conforming to expressive or rhetorical design logic in a friendship context (Hullman, 2004). Control-motivated communication is negatively related to a self-reported attentive style of communication, but positively related to dominant and dramatic styles of communication. Communicating for control negatively relates to smiling and sitting close to others, and having a relaxed body position (Myers \& Ferry, 2001). It seems logical to expect that communicating for control would be associated with more dominant relational messages and fewer affiliative messages. For this reason, we predict:

H1: Speakers of control motivated messages will display more relational messages indicating dominance and fewer relational messages indicating affiliation.

\section{INCLUSION}

Inclusion "is a need to be with and share feeling with others, and to alleviate loneliness" (Graham et al., 1993, p. 173). Communicating for inclusion is positively related to an external locus of control (Rubin \& Rubin, 1992), extraversion, and neuroticism. For older adults, communicating for inclusion is positively related to moderate levels of loneliness (Downs \& Javidi, 1990). However, communicating for inclusion is negatively related to psychoticism (Paulsel \& Mottett, 2004).

Generally, people look to closer relationships for inclusion (Barbato \& Perse, 1999; Anderson, Martin, \& Zhong, 1998) as opposed to strangers and co-worker relationships (Graham et al., 1993). People do, however, report communicating with their bosses for inclusion reasons (Anderson \& Martin, 1995b). In addition, in a small group setting, communicating for inclusion is positively related to group satisfaction (Anderson \& Martin, 1995a).

Inclusion messages were judged most appropriate when they were framed in an expressive design logic (Hullman, 2004), which is typified by more free-flowing thoughts and words. Inclusion is positively related to a friendly, animated communication style (Graham et al., 1993), but also positively related to speaking in a monotone voice (Myers \& Ferry, 2001).

Because inclusion motivated messages are related to becoming closer to others developing more intimate relationships, the following hypothesis is posed:

$\mathrm{H} 2$ : Speakers of inclusion motivated messages will display fewer relational messages indicating dominance and more relational messages indicating affiliation.

\section{AFFECTION}

Affection means communicating for the purpose of "showing appreciation and concern for others" (Graham et al., 1993, p. 173). Communication for affection reasons occurs mainly in close relationships (such as friendships; Anderson et al., 1998), rather than with strangers. For example, communicating for affection is linked to conformity family communication orientation (Barbato et al., 2003). Fathers reported communicating with their young adult children for affection reasons, which was also positively related to satisfaction with the relationship (Martin \& Anderson, 1995). Barbato and Perse (1999) also found support for parents communicating for affection reasons.

Despite the initial finding that communicating for affection occurs mainly in intimate relationships, Anderson and Martin (1995b) found that people communicate with their bosses for affection purposes. For subordinates, Machiavellianism is negatively related to communicating for affection; however, communicating for affection purposes with a superior is positively linked to satisfaction with that superior (Walter et al., 2005). Those who communicate for affection in small groups also tend to be more perceptive, responsive, attentive and satisfied with the group (Anderson \& Martin, 1995a).

A few studies have reported results based specifically on elderly samples. First, elderly communicators who communicate for affection tend to use humor (Barbato et al., 1997). Barbato and Perse (1992) found that those with who were more satisfied with their lives and experienced more social activity also communicated more for affection reasons. Similarly, Rubin and Rubin (1992) also found that those who were socially active, satisfied with their lives, and healthy communicated for affection reasons. Moderate levels of loneliness were associated with older adults communicating for affection reasons (Downs \& Javidi, 1990).

Affection motivated messages are judged more competent when framed in either an expressive or conventional design logic, rather than in a rhetorical design logic (Hullman, 2004). Communicating for affection also is 
Table 1. Means of Motive by Video Clip in Pilot Study

\begin{tabular}{|c|c|c|c|}
\hline & Control & Inclusion & Affection \\
\hline \hline Control 1 & $2.40_{\mathrm{a}}$ & $4.73_{\mathrm{a}}$ & $5.23_{\mathrm{a}}$ \\
\hline Control 2 & $3.03_{\mathrm{ab}}$ & $4.84_{\mathrm{a}}$ & $4.80_{\mathrm{b}}$ \\
\hline Control 3 & $2.20_{\mathrm{ab}}$ & $4.82_{\mathrm{a}}$ & $4.83_{\mathrm{b}}$ \\
\hline Inclusion 1 & $4.85_{\mathrm{a}}$ & $1.90_{\mathrm{a}}$ & $2.60_{\mathrm{a}}$ \\
\hline Inclusion 2 & $4.75_{\mathrm{a}}$ & $2.61_{\mathrm{a}}$ & $3.90_{\mathrm{a}}$ \\
\hline Inclusion 3 & $5.75_{\mathrm{a}}$ & $1.30_{\mathrm{a}}$ & $2.61_{\mathrm{a}}$ \\
\hline Affection 1 & $4.67_{\mathrm{a}}$ & $2.50_{\mathrm{a}}$ & $3.78_{\mathrm{a}}$ \\
\hline Affection 2 & $5.23_{\mathrm{a}}$ & $2.74_{\mathrm{a}}$ & $3.79_{\mathrm{a}}$ \\
\hline
\end{tabular}

Means with common subscripts across rows are significantly different from one another $(<.05)$

related to a friendly, attentive, non-dramatic communication style (Graham et al., 1993). Those who communicate to show affection also use gestures, touch their conversational partners, use vocal variety, and have a relaxed body position (Myers \& Ferry, 2001). Communicating for affection is positively related to extraversion and negatively related to psychoticism (Paulsel \& Mottett, 2004). These behaviors are indicative of more intimate relationships and people moving closer to one another. Therefore, we pose the following research question:

H3: Speakers of affection motivated messages will display fewer relational messages indicating dominance and more relational messages indicating affiliation.

\section{METHOD}

Researchers gathered a list of foreign films from a university library. Nine films (Amelie, Ceravamo Tanto Amati, House of Fools, A Woman is a Woman, The Obscure Object of Desire, Ikiru, House of Flying Daggers, The Leopard, and La Strada) were randomly chosen as was one scene from each of the nine films. A focus group of 6 graduate students viewed the clips and discussed whether or not the main character of the clip was communicating for one of the three main interpersonal communication motives (control, inclusion, and affection). Additional, subsequent clips were examined, until all motives were represented by three clips. The goal was to have all three motives represented by more than one clip to avoid a case confounding category (Jackson, 1992).

\section{PILOT STUDY}

Participants $(N=22)$ of traditional college age $(M=$ 21.73; $S D=5.06)$ and mainly female $(60 \%)$ viewed the video clips and English subtitles in a pilot study. They rated the main character's motivation according to the randomly ordered items representing the control, inclusion, and affection motives in the Interpersonal Communication Motives Instrument (Rubin et al., 1988). The Interpersonal Communication Motives Instrument (ICMS) is a 28-item instrument Likert-type scale assesses six main the reasons why people talk one another (control, inclusion, affection, relaxation, pleasure, and escape). Because this project focused on the primary communication motives (e.g., control, inclusion, and affection), only the 12 items for those subscales were included in the current project.

Participants in the pilot study viewed 9 video clips (three representing each primary motive) and the English subtitles before rating how much the character's reasons for communicating were like the reasons listed in the ICMS subscales from 1 (strongly agree) to 6 (strongly disagree). We chose foreign films that represented a variety of languages (e.g., French, Italian, German). Titles of the films are: Weeping Camel, Guaguasi, Burnt by the Sun, Avenue Montaigne, and La doublure. Clips were chosen using stratified random sampling technique until 3 clips for each motive were identified. The films are all characteristic of contemporary realism, as opposed to silent film, restoration drama, or absurdism. The advantage to using contemporary realistic works is that they have a foundation in naturalistic acting, which purports a truthful, honest method of performance. Stanislavsky advocated a modern, realistic approach to acting, which has become quite popular in film today (Wilson, 2011).

Participants in the pilot study had the added benefit of watching the verbal component of the message, which was later removed for the manipulation. One-tailed paired sample t-tests corrected for multiple comparisons using the Bonferroni correction assessed differences. (Please see Table 1 for means and standard deviations). Means for control in the control-motivated clip were significantly higher than means for inclusion in all three control clips $(t(22)=9.38, p$ $=.00 ; t(22)=9.38, p=.00) ; t(22)=9.38, p=.00)$ and significantly higher than the means for affection $(t(22)=$ 9.36, $p=.00 ;(t(22)=5.63, p=.00 ; t(22)=11.02, p=.00)$. The means for inclusion were significantly higher for the inclusion clips than the means for control $(t(22)=6.46, p=$ $.00 ; t(22)=9.38, p=.00 ; \mathrm{t}(22)=11.69, p=.00)$ and affection $((t(22)=3.08, p=.00 ; t(22)=11.56, p=.00) ; t(22)$ $=7.00, p=.00)$. Two means for the affection clips were higher than the control $(t(22)=3.26, p=.00 ; t(22)=3.39, p$ $=.00)$ and inclusion $(t(22)=6.04, p=.00 ; t(22)=3.40, p=$ .00) means for the affection clips. One of the three clips representing affection elicited similar mean scores for both inclusion $(M=4.70)$ and affection $(M=4.46)$, and was insignificant $(t(113)=1.05, p=.30)$. Therefore, the third affection clip was discarded. The eight retained video clips represented a reflection of one motive significantly more than a reflection of the other two motives. The eight video clips were then used in the manipulation.

\section{MANIPULATION}

Recruitment took place in a classroom environment. Students who wished to volunteer for the study stayed after class to complete the survey, which took about 20 minutes. In total, 116 participants ( $81 \%$ female) of traditional college age $(M=22, S D=3.45)$ completed the survey.

Responses to statements about characters' communication in foreign video clips constituted the data for this study. Participants viewed foreign film clips as a way to isolate the nonverbal communication from the verbal component of the message. Using characters who speak a language different from the participants' primary language allowed the vocalic cues to be included without the verbal 
Table 2. Paired Sample T-tests for Affiliative and Dominant Relational Messages by Motive

\begin{tabular}{|c|c|c|c|}
\hline & Control & Inclusion & Affection \\
\hline \hline \multirow{2}{*}{ Dominance } & 4.04 & 4.03 & 4.26 \\
& $\mathrm{SD}=.52$ & $\mathrm{SD}=.54$ & $\mathrm{SD}=.60$ \\
\hline \multirow{2}{*}{ Affiliation } & 4.22 & 3.70 & 3.97 \\
& $\mathrm{SD}=.46$ & $\mathrm{SD}=.44$ & $\mathrm{SD}=.57$ \\
\hline
\end{tabular}

Note. $N=113$. Possible score ranges are from 1 (more affiliative or dominant) to 7 (less affiliative or dominant). Means down columns are significantly different at the .001 level. Multiple comparisons were corrected with the Bonferroni correction.

language cues. Participants viewed eight 30-second video clips in which a language other than English was spoken. Eight video clips represented one of 3 interpersonal communication motives: control, inclusion, and affection. The video clips were embedded into a power point presentation. The slide before each video clip described the character to be evaluated. The slide after each video clip referred participants to questions relevant to that video clip. After each video clip, participants rated the main character's behavior on affiliation and dominance. The survey also included a written prompt indicating which character to rate for each clip.

One of three versions of the order of the video clips was randomly assigned to each class of students who completed the video clip assessment. Four participants previously viewed one of the films before so their responses were not included for those clips. In addition, four participants spoke French, five spoke Italian, and one spoke German, so their responses were not included in the means for the respective clips because they essentially understood all cues present in the video clips.

\section{RELATIONAL MESSAGES}

Items from Burgoon and Hale's (1984) Relational Dimensions Instrument comprised the indicators for affiliative and dominant relational messages. Dillard et al., (1999) suggested that similarity, affect, receptivity, and equality could be collapsed into an affiliative dimension. Dominance-related items loaded separately onto their own dimension. Items $(n=16)$ representing the affiliative dimensions were then averaged for the affiliative score $(\alpha=$ .78) for each clip. Items representing the dominance dimension $(n=4)$ were averaged for the dominance score $(\alpha$ $=.85$ ) for each clip.

\section{RESULTS}

Scores for relational messages were combined across motive to form three groups: control, inclusion, and affection. Paired Sample t-tests corrected for multiple comparisons using the Bonferroni correction were used to determine if differences among the two themes of relational messages (i.e., dominance and affiliation) were evident based upon the motive. Table 2 summarizes the results.

\section{DOMINANCE}

Hypothesis 1 stated that control motivated communicators would display significantly more dominant nonverbal relational messages than affiliative nonverbal relational messages. Hypothesis one was supported. As predicted, control motivated communicators displayed significantly more dominant nonverbal messages $(M=4.04$, $S D=.53)$ than affiliative nonverbal messages $(M=4.21, S D$ $=.46), t(115)=3.38, p=.00($ one-tailed $)$ ).

Hypothesis 2 stated that inclusion motivated communicators would display significantly more affiliative nonverbal relational messages than dominant nonverbal relational messages. Hypothesis 2 was supported. As predicted, inclusion motivated communicators displayed significantly more affiliative nonverbal relational messages $(M=3.71, S D=.44)$ than dominant relational messages $(M$ $=4.03, S D=.46, t(113)=-6.20, p=.00$ (one-tailed)).

Hypothesis 3 stated that affection motivated communicators would display significantly more affiliative nonverbal relational messages than dominant nonverbal relational messages. Hypothesis 3 was supported. Affection motivated communicators displayed significantly more affiliative nonverbal messages $(M=3.97, S D=.57)$ than dominant nonverbal relational messages $(M=4.26, S D=$ $.60, t(113)=-4.34, p=.00$, one-tailed)).

\section{DISCUSSION}

The purpose of this study was to determine whether or not messages sent to fulfill certain motives were accompanied by complementary relational messages of affiliation and dominance. For the motives of control, inclusion, and affection, congruent nonverbal relational messages accompany the verbal components of the message.

The results extend the work of those interested in describing how motives manifest themselves in communication messages. Normally thought of only as antecedents of a message, motives also affect what the message looks like. Motivation affects both the effectiveness and appropriateness of verbal structure (Hullman, 2004) of the message and the nonverbal relational messages that are sent. This finding mirrors the self-report data summarized by Myers and Ferry (2001) indicating that those who state they communicate for control also report using less immediate nonverbal behaviors. On the other hand, those who communicate more for affection report using more immediate nonverbal behaviors, such as smiling and sitting close to their conversational partners.

The results of the present support that people display behaviors congruent to the reason for which they are communicating. Displaying nonverbal behaviors that create an impression consistent to the reason for communicating might be a more efficient way to send a message to another person. For example, Burgoon and Bacue (2003) stated that when the verbal and nonverbal elements of messages disagree, interpretation becomes more difficult. In addition, Rosenthal and DePaulo (1979) suggested that people can more accurately decode unmixed, rather than mixed messages. In terms of easing understanding, congruent messages are superior to incongruent messages.

Although nonverbal relational messages were congruent with the speakers' motivations in this study, other evidence suggests that at times, persuasive or controlling messages might be more effective when accompanied by more immediate nonverbal behaviors that create an affiliative 
impression (Schrader, 1994). Investigating speakers' choices and effects of incongruent messages provides an avenue for future research.

Despite its contribution to interpersonal research, this study is not without its limitations. First, traditional college students from one university rated the relational messages. Perhaps including a more diverse sample would allow us to generalize the findings better. Second, participants rated the motives and behaviors of professional actors in foreign films as opposed to face -to-face interactions representing 'real life.' Presenting 'real life' scenarios to participants in the future would increase ecological validity.

Despite the limitations, this study supports a relationship between communication motivation and displayed relational messages. Nonverbal relational messages are packaged in ways that illustrate dominance for control-motivated messages, and affiliation for inclusion and affectionmotivated messages.

\section{CONFLICT OF INTEREST}

None declared.

\section{ACKNOWLEDGEMENT}

None declared.

\section{REFERENCES}

Adaval, R., \& Wyer, R.S., (2004). Communicating about a social interaction: Effects on memory for protagonists' statements and nonverbal behavior. Journal of Experimental Social Psychology, 40, 450-465.

Anderson, C.A., Martin, M.M. (1995a). The effects of communication motives, interaction involvement, and loneliness on satisfaction: A model of small groups. Small Group Research, 26, 118-137.

Anderson, C.A., \& Martin, M.M. (1995b). Why employees speak to coworkers and bosses: Motives, gender, and organizational satisfaction. The Journal of Business Communication, 32, 249-265.

Anderson, C.A., Martin, M.M., \& Zhong, M. (1998). Motives for communicating with family and friends: A Chinese study. The Howard Journal of Communications, 9, 109-123.

Barbato, C.A., Graham, E.E., \& Perse, E.M. (2003). Communicating in the family: An examination of the relationship of family communication climate and interpersonal communication motives. The Journal of Family Communication, 3(3), 123-148.

Barbato, C.A., Graham, E.E., \& Perse, E.M. (1997). Interpersonal communication motives and perception of humor among elders. Communication Research Reports, 14, 48-57.

Barbato, C.A., \& Perse, E.M. (1992). Interpersonal communication motives and the life position of elders. Communication Research, 19, 516531.

Barbato, C.A., \& Perse, E.M. (1999). "I don't care if you are 65, you're still my baby!": Examining parents' motives throughout the lifespan. Communication Research Reports, 16, 147-156.

Boderman, A., Freed, D.W., \& Kinnucan, M.T. (1972). Touch me, like me: Testing an encounter group assumption. Journal of Applied Behavioral Science, 8, 527-533.

Burgoon, J.K. (1991). Relational message interpretations of touch, conversational distance, and posture. Journal of Nonverbal Behavior, 15, 233-259.

Burgoon, J.K. (1994). Nonverbal Signals. In: Knapp, M., \& Miller, G. (Eds.), The Handbook of Interpersonal Communication (pp. 229285). Thousand Oaks, CA: Sage.

Burgoon, J.K., Buller, D.B., Hale, J.L., \& deTurck, M.A. (1984). Relational messages associated with nonverbal behaviors. Human Communication Research, 10, 351-378.

Burgoon, J.K., Coker, D.A., \& Coker, R.A. (1986). Communicative effects of gaze behavior: A test of two contrasting explanations. Human Communication Research, 12, 495-524.
Burgoon, J.K., Kelley, D.L., Newton, D.A., \& Keeley-Dyreson, M.P. (1989). The nature of arousal and nonverbal indices. Human Communication Research, 16, 217-255.

Burgoon, J.K., \& LePoire, B.A. (1999). Nonverbal cues and interpersonal judgments: Participants and observer perceptions of intimacy, dominance, composure, and formality. Communication Monographs, 66, 104-124.

Burgoon, J.K., \& Newton, D.A. (1991). Applying a social meaning model to relational messages of conversational involvement. Southern Communication Journal, 56, 96-113.

Burgoon, J.K., \& Hale, J.L. (1987). Validation and measurement of the fundamental themes of relational communication. Communication Monographs, 54, 19-41.

Burgoon, J.K., Walther, J.B., \& Baesler, E.J. (1992). Interpretations, evaluations, and consequences of interpersonal touch. Human Communication Research, 19, 237-263.

Capella, J.N. (1983). Conversational Involvement: Approaching and Avoiding Others. In: Wiemann, J.M., \& Harrison, R.P. (Eds.), Nonverbal Interaction (pp. 113-148). Beverly Hills, CA: Sage.

Coker, D.A., \& Burgoon, J.K. (1987). The nature of conversational involvement and nonverbal encoding patterns. Human Communication Research, 13, 463-494.

Dillard, J.P., Solomon, D.H., \& Palmer, M.T. (1999). Structuring the concept of relational communication. Communication Monographs, 66, 49-65.

Downs, V.C., \& Javidi, M. (1990). Linking communication motives to loneliness in the lives of older adults: An empirical test of interpersonal needs and gratifications. Journal of Applied Communication Research, 18, 32-48.

Fisher, J.D., Rytting, M., \& Heslin, R. (1975). Hands touching hands: Affective and evaluative effects of interpersonal touch. Sociometry, $39,416-421$.

Fussell, S., \& Krauss, R. (1992). Coordination of knowledge in communication: effects of speakers' assumptions about what others know. Journal of Personality and Social Psychology, 62(3), 378391.

Graham, E.E., Barbato, C.A., \& Perse, E.M. (1993). The interpersonal communication motives model. Communication Quarterly, 41, $172-186$.

Hullman, G.A. (2004). Interpersonal communication motives and message design logic: Exploring their interaction on perceptions of competence. Communication Monographs, 71, 208-225.

Jackson, S. (1992). Message Effects Research: Principles of Design and Analysis. New York: Guilford Press.

Katz, E., Blumler, J.G., Gurevitch, M. (1974). Utilization of Mass Communication by the Individual. In: Blumter, J.G., \& Katz, E. (Eds.), The Uses of Mass Communications: Current Perspectives on Gratifications Research (pp. 19-32). Beverly Hills: Sage.

Lau, I., \& Chiu, C. (2001). I know what you know: assumptions about others' knowledge and their effects on message construction. Social Cognition, 19, 587-600.

Martin, M.M., \& Anderson, C.A. (1995). The father-young adult relationship: Interpersonal motives, self-disclosure, and satisfaction. Communication Quarterly, 43, 119-130.

Mehrabian, A. (1969). Significance of posture and position in the communication of attitude and status relationships. Psychological Bulletin, 71, 359-372.

Myers, S.A., \& Ferry, M. (2001). Interpersonal communication motives and nonverbal immediacy behaviors. Communication Research Reports, 18, 182-191.

Paulsel, M.L., \& Mottet, T.P. (2004). Interpersonal communication motives: A communibiological perspective. Communication Quarterly, 52, 182-195.

Rosenthal, R., \& DePaulo, B.M. (1979). Expectancies, discrepancies, and courtesies in nonverbal communication. Western Journal of Speech Communication, 43, 76-95.

Rubin, R.B., \& Martin, M.M. (1998). Interpersonal Communication Motives. In: McCroskey, J.C., Daly, J.A., Martin, M.M., \& Beatty, M.J. (Eds.), Communication and Personality: Trait Perspectives (pp. 287-307). Cresskill, NJ: Hampton Press.

Rubin, R.B., Perse, E.M., \& Barbato, C.A. (1988). Conceptualization and measurement of interpersonal communication motives. Human Communication Research, 14, 602-628.

Rubin, A.M., \& Rubin, R.B. (1985). Interface of personal and mediated communication: A research agenda. Critical Studies in Mass Communication, 2, 36-53. 
Schrader, D.C. (1994). Judgments of acceptable partners for social goals based on perceptions of nonverbal behavior. Journal of Social Behavior and Personality, 9, 353-364.

Siegman, A.W. (1978). The Telltale Voice: Nonverbal Messages of Verbal Communication. In: Siegman, A.W., \& Feldstein, S. (Eds.), Nonverbal Behavior and Communication (pp. 183-243). Hillsdale, NJ: Lawrence Erlbaum.

Schutz, W.C. (1966). The Interpersonal Underworld. Palo Alto, CA: Science and Behavior Books.
Thayer, S. (1986). The psychology of touch [Special issue]. Journal of Nonverbal Behavior, 10, 7-80.

Walter, H.L., Anderson, C.A., \& Martin, M.M. (2005). How subordinates Machiavellianism and motives relate to satisfaction with superiors. Communication Quarterly, 53, 57-70.

Wilson, E. (2011). The Theatre Experience (12 ${ }^{\text {th }}$ ed.) New York: McGraw Hill.

Received: September 07, 2011

Revised: December 02, 2011

Accepted: December 08, 2011

(C) Hullman et al.; Licensee Bentham Open.

This is an open access article licensed under the terms of the Creative Commons Attribution Non-Commercial License (http://creativecommons.org/licenses/by-nc/3.0/) which permits unrestricted, non-commercial use, distribution and reproduction in any medium, provided the work is properly cited. 